\title{
The old and the new: an enhanced vision for JNA
}

The publication of this issue of JNA coincides with the 2018 Annual Meeting of the Society for Neuroscience in Anesthesia and Critical Care (SNACC), and includes the abstracts that will be presented at the meeting. ${ }^{1}$ The mission of SNACC is to advance the art and science of the care of the neurologically impaired patient through education, training and research in perioperative neuroscience, and the Society's enthusiasm for, and excellence in, science enables JNA to be a key partner in delivering this mission. That SNACC is able to attract 121 diverse and high-quality submissions for presentation at its meeting reflects both its' broad reach and also the importance that established and more junior neuroscience researchers alike place on this forum for presentation of their work. Thus, I am encouraged by the enthusiasm of the SNACC leadership to develop further the relationship between the Society and the Journal. This year, for the first time, the SNACC Annual Meeting will include a 'JNA Year in Review' session, and I am grateful to the organisers for allocating time for the Journal to be showcased and for us to debate how we can work together for mutual benefit.

Many of you have experienced first-hand the changes in the clinical practice of neuroanesthesiology and neurocritical care that have taken place over recent years, and the key contributions that neuroanesthesiologists and neurointensivists now make to perioperative neuroscience more broadly. These changed emphases are reflected in the 2018 SNACC meeting program and abstracts, and it is equally important that they become reflected in the content of JNA. To this end the scope of the journal has been clarified and extended to encompass the whole of perioperative neuroscience and related basic science, and to align more closely with the 'three pillars' of neuroanesthesiology recently popularized by SNACC. ${ }^{2}$ Specifically the journal aims to attract high-quality submissions in areas related to clinical neuroanesthesiology and neurocritical care, foundational neuroscience of anesthesiology and brain and spinal cord injury, and neurologic outcomes after non-neurologic 
surgery and critical illness. You will see articles dealing with all of these topic areas appearing in JNA during the next year.

I anticipate that the new content will increase the Journal's relevance to its current readership, but also hope that it will broaden its appeal. While the vision laid out by the foundation Editor-in-Chief and Associate Editor in the inaugural issue of JNA - to bring together relevant information for neuroanesthesiologists, neurointensivists and basic neuroscientisists within a single Journal- is as relevant today as it was in $1989,{ }^{3}$ I believe that the Journal's content now extends beyond that original target audience. However, for the Journal to develop and prosper I need to understand better the needs of its readers and authors. Please contact me by email with opinions and ideas or, in person, at the SNACC meeting.

I wish SNACC and its members a successful Annual Meeting, and look forward to seeing many of you in San Francisco.

\section{References}

1. Abstracts from the 46th Annual Meeting of the Society for Neuroscience in Anesthesiology and 470

2. Smith M. Editorial. J Neurosurg Anesthesiol 2018; 30: 1

3. Cottrell J, Hartung J. On the need for a new journal. J Neurosurg Anesthesiol 1989; 1: 1-2

Martin Smith

martin.smith@ucl.ac.uk 